\title{
ВОПРОСЫ СОВЕРШЕНСТВОВАНИЯ НАЛОГОВОГО АДМИНИСТРИРОВАНИЯ В АЗЕРБАЙДЖАНЕ
}

\begin{abstract}
Аннотация. В данном исследовании автор рассматривает проблемы совершенствования налоговой системы, ее взаимосвязь между основными звеньями налогового администрирования, анализируются этапь развития налогового администрирования в Азербайджане и современное ее состояние. На современном этапе организация налогового дела в налоговых органах происходит посредством карты рабочих процессов. Основная задача на данном этапе является совершенствование данных рабочих процессов, основных направлений информационно-технологического климата, эффективности налогового администрирования.

Ключевые слова: Налоги и налогообложение, налоговая система, налоговое администрирование, одно окно, депозитный счет, налоговый контроль, электронные услуги, счет-фактура, электронный аудит, налоговые органы.
\end{abstract}

Review: The author of the present research views the problems of improvement of taxation system, describes relations between the main elements of tax administration and analyzes the main stages of development of tax administration in Azerbaijan as well as the actual status of tax administration there. At the present stage tax authorities perform taxation by using operational process charts. At this point the main goal should be the improvement of these operational processes, technological environment and efficiency of tax administration.

Keywords: taxes and taxation, taxation system, tax administration, one-stop shop, deposit account, tax control, e-services, proforma invoice, e-audit, tax authorities.

становление общественно-политической стабильности в независимом Азербайджане и возрождение национальной экономики на основе новых имущественных отношений стало возможно после возвращения общенационального лидера Гейдара Алиева к политической власти в Азербайджане в 1993 г. Коренные реформы во всех сферах, в том числе и в налоговой системе, и экономический рост связаны исключительно с его именем. В рамках стратегии развития, определенной общенациональным лидером, и которая успешно продолжается под руководством президента Азербайджана Ильхама Алиева, углубляются экономиче- ские реформы, создана возможность для прогресса во всех отраслях экономики и повышения международного авторитета страны. Значительный экономический потенциал, внедренные гибкие и эффективные механизмы, привели к тому, что начавшийся в 2008 г. в мире глобальный финансовый кризис не оказал влияния на макроэкономическое развитие и финансовую стабильность экономики Азербайджана. Основной причиной этого является проведение государством эффективных мероприятий в рамках экономической политики с целью предупреждающей нейтрализации возможных факторов риска в экономике, в том числе в деятельности 
DOI: $10.7256 / 1812-8688.2013 .12 .4468$

При цитировании этой статьи сноска на doi обязательна

Налоговые системы зарубежных стран

предприятий. Одним из таких мероприятий является освобождение с 1 января 2009 г. сроком на три года той части налога на прибыль, которую банки, страховые и перестраховочные компании направляют на повышение уставного капитала. Этот шаг преследует цель ускорить развитие финансового сектора, укрепить платежеспособность банков и страховых компаний, повысить уровень их капитализации. В тоже время, согласно последним изменениям, внесенным в Налоговый Кодекс, с 1 января 2010 г. ставка налога на прибыль составит 20\% ${ }^{1}$. Необходимо заметить, что с целью расширения инвестиционных возможностей и увеличения финансовых средств предприятий ставка налога на прибыль в 2003-2006 гг. поэтапно была снижена с 27\% до $22 \%$. Опыт прошлых лет показывает, что снижение ставок налогов приводит к уменьшению налогового бремени. В то же время, предприятия в результате снижения ставок налогов получают дополнительные оборотные средства и посредством реинвестиций могут получить дополнительный доход. Это, в свою очередь, создает возможность образования дополнительной базы для налогообложения. Таким образом, снижение ставки налогообложения приводит к расширению базы налогообложения. Практическим результатом всего этого является рост налоговых поступлений.

Другим существенным изменением, направленным на социальную защиту и улучшение материального положения населения, является снижение максимальной ставки подоходного налога с $35 \%$ до $30 \%$. Согласно действующему законодательству, чтобы стать плательщиками НДС, юридические лица в течение 12 месяцев должны иметь оборот, подлежащий налогообложению, в размере 150

\footnotetext{
${ }^{1}$ Налоговый Кодекс Азербайджанской Республики. Баку: 2010
}

тыс. манатов, физические лица - 90 тыс. манатов $^{2}$. В целом, все эти мероприятия направлены на стимулирование развития экономики, в том числе реального сектора, усиления социальной защиты населения, дальнейшего улучшения инвестиционного климата.

Приказом Министерства по Налогам с 10 марта 2009 г. по 31 марта 2009 г. приостановлено проведение выездных налоговых проверок и наблюдений методом хронометража у налогоплательщиков, осуществляющих деятельность в некоторых сферах. Правда, данный шаг можно расценивать еще, как и предупреждающие действия, направленные на снижение возможного влияния мирового финансового кризиса на экономику Азербайджана. Но считаем, что самым важным в этом решении, является психологический аспект. Можно согласиться с тем, что сегодня дискуссии, связанные с финансовым кризисом являются наиболее актуальными. Каждый из нас оказывается под воздействием информации, связанной с результатами этого кризиса, его продолжительностью, возможными потерями. Для экономики это является не столь желательным, так как может привести к сокращению экономической активности. В такие моменты важно оказать помощь микросубъектам в экономике, особенно застраховать частный сектор от этого влияния, по возможности восстановить веру предпринимателей в будущее, предотвратить общий спад уровня инвестиционных вложений и экономической активности. Необходимо обратить внимание на тот факт, что финансовому кризису оказались менее подвержены и смогли быстро выйти из-под этого влияния те страны, в которых экономические субъекты доверяли государственным институтам, и где не наблюдалось снижения экономической

\footnotetext{
${ }^{2} 1$ манат $(\mathrm{AZN})=1,2$ долл. США или же 1 манат $(\mathrm{AZN})=39.2638$ RUR
} 
активности. То есть в этом случае уместно говорить о психологическом уверенности субъектов предпринимательства.

В стране ускоренно развиваются информационно-коммуникационные технологии, реализуются важные работы в направлении создания «Электронного правительства»1. Согласно Государственной программе по развитию связи и информационных технологий в Азербайджане в 2005-2008 годах (Электронный Азербайджан)»², утвержденной распоряжением президента, Министерства по налогам также постоянно расширяет охват предоставляемых налогоплательщикам электронных услуг. Новый этап развития налоговой системы начался с распоряжения Президента Азербайджана от 12 сентября 2005 г. об утверждении «Государственной программы совершенствования налогового администрирования в Азербайджанской Республике на 20052007 гг.»3. Так, в 2006 г. при Министерстве по Налогам была создана Автоматизированная налоговая информационная система (AVİS), a в 2007 г. Интернет налоговое управление www.e-taxes.gov.az), также с банками начался обмен электронными документами и прием налоговых деклараций в электронной форме, была установлена компьютерные терминалы в регионах, расширена зона охвата телефонной информационной службы.

С начала 2009 г. в налоговой системе началась реализация «Стратегического плана

\footnotetext{
1 Закон Азербайджанской Республики «Об электронной подписи и электронном документе». Баку, 4 марта 2004 г.

2 Указ Президента Азербайджанской Республики об утверждении Государственной Программы на 2005 2008 гг. по развитию связи и информационных технологий Азербайджанской Республики (Электронный Азербайджан). Баку, 21 октября 2005 г.

${ }^{3}$ Распоряжения Президента Азербайджана от 12 сентября 2005 г. об утверждении «Государственной программы совершенствования налогового администрирования в Азербайджанской Республике на 2005-2007 гг.».
}

совершенствования налогового законодательства и администрирования на 2009-2012 гг.» ${ }^{4}$. Этот План предусматривает проведение в ближайшие три года в налоговой системе новых и качественных изменений. Например, согласно Стратегическому Плану с целью дальнейшего совершенствования налогового администрирования в сфере НДС, с 1 января 2010 г. начался применение электронных счетов-фактур.

Внедрением депозитных счетов НДС были созданы условия для реализации оплаты НДС в электронной форме по купленным у других налогоплательщиков товарам (работам и услугам), а также по импортированным в страну товарам.

Постановлением Кабинета Министров Азербайджанской Республики за № 219 от 30 декабря 2007 г. утверждены правила уплаты НДС при оплате стоимости товаров (работ и услуг), приобретенных по налоговому счету-фактуре, выданному налогоплательщику, ведения учета на депозитном счету НДС, движения НДС, возмещения НДС с операций, совершаемых по этому счету, и его перечисления в государственный бюджет, которые введение в действте с 1 января 2008 г. ${ }^{5}$

Утверждены «Правила уплаты НДС при оплате стоимости товаров (работ и услуг), приобретенных по налоговому счету-фактуре, выданному налогоплательщику, ведения учета на депозитном счету НДС, движения НДС,

\footnotetext{
4 «Стратегический план совершенствования налогового законодательства и администрирования на 2009-2012 гг.», принятый Министерством Налогов Азербайджанской Республики. Баку, 2009 г.

${ }^{5}$ Постановление Кабинета Министров Азербайджанской Республики «Об утверждении Правил уплаты НДС при оплате стоимости товаров (работ и услуг), приобретенных по электронному налоговому счету-фактуре, выданному налогоплательщику, ведения учета на депозитном счету НДС, движения НДС, возмещения НДС с операций, совершаемых по этому счету, и его перечисления в государственный бюджет». Баку, 30 декабря 2007 года.
} 
DOI: $10.7256 / 1812-8688.2013 .12 .4468$

При цитировании этой статьи сноска на doi обязательна

Налоговые системы зарубежных стран

возмещения НДС с операций, совершаемых по этому счету, и его перечисления в государственный бюджет и на открытый в казначейских органах соответствующий депозитный счет государственных таможенных органов». ${ }^{1}$

Денежные средства с депозитного счета НДС перечисляются в государственный бюджет и на открытый в казначейских органах соответствующий депозитный счет государственных таможенных органов на основании платежного поручения, подготовленного Министерство Налогов Азербайджанской Республики в централизованном порядке, в следующих случаях:

- для уплаты налогового обязательства, процентов и примененных финансовых санкций по налогу на добавленную стоимость;

- на основании официального обращения налогоплательщика.

Средства на субучетный счет НДС налогоплательщика поступают из источников и из иных субучетных счетов НДС.

Перечисление сумм НДС с субучетного счета НДС осуществляется в следующей последовательности:

- в государственный бюджет;

- на открытый в казначейских органах соответствующий депозитный счет государственных таможенных органов;

- на субучетные счета НДС.

На основании полученного налогового счета-фактуры покупатель может перечислить сумму НДС со своего субучетного счета НДС на субучетный счет продавца. Для совершения данного платежа покупатель посредством специального пароля-шифра, полученного от налогового органа в соответ-

${ }^{1}$ Постановление Кабинета Министров Азербайджанской Республики Об утверждении «Правил применения, учета и использования электронных налоговых счет-фактур». Баку, 28 сентября, 2009 г. ствии с постановлением Кабинета министров Азербайджанской Республики от 27 июля 2007 г. № 120, заходит в Налоговое Интернетуправление (www.e-taxes.gov.az) и совершает платеж, используя созданное меню «Совершение операций по перечислению»². После завершения операции покупатель посредством программного обеспечения может распечатать извещение о совершении перечисления. Продавец вправе потребовать у покупателя извещение, подтверждающее совершение перечисления с субучетного счета НДС.

Используя специальный пароль-шифр, полученный от налоговых органов, налогоплательщики, наряду с совершением операций по своим субучетным счетам НДС в режиме реального времени, могут также получить сведения об операциях, совершенных по этим субучетным счетам НДС и сальдо.

Налогоплательщик может осуществлять платежи по налогам в государственный бюджет и на открытый в казначейских органах соответствующий депозитный счет государственных таможенных органов с субучетного счета, неизвестного субучетного счета НДС. В этом случае Министерство Налогов Азербайджанской Республики обязано обеспечить отражение данных средств в платежном поручении.

В случае совершения налогоплательщиком платежа НДС за товары, ввозимые в соответствии с грузовыми таможенными декларациями, на открытый в казначейских органах соответствующий депозитный счет государственных органов с субучетного счета НДС, Министерство Налогов Азербайджанской Республики представляет платежное поруче-

\footnotetext{
${ }^{2}$ Постановление Кабинета Министров Азербайджанской Республики «Об утверждении Порядка отправления налоговой отчетности в форме электронного документа». Баку, 27 июля 2007 г.
} 
ние в электронном формате в порядке, отразив в нем наименование, идентификационный номер налогоплательщика (ИНН) совершивших платеж налогоплательщиков, номер открытого в казначейских органах соответствующего депозитного счета государственных таможенных органов и сумму платежа.

Аннулирование учета НДС налогоплательщика является основанием для ограничения его пользования субучетным счетом НДС. При аннулировании учета НДС налогоплательщика денежные средства, находящиеся на его субучетном счету НДС и поступившие позднее на данный субучетный счет, перечисляются в государственный бюджет, и вносятся в карточку лицевого счета данного налогоплательщика в налоговом органе.

При ликвидации юридического лица в результате слияния, присоединения и разделения денежные средства, находящиеся на его субучетном счету НДС, перечисляются на субучетные счета НДС реорганизованных юридических лиц, находящихся на учете НДС, или в государственный бюджет.

Применение депозитного счета по НДС, прежде всего, направлено на совершенствование механизма контроля со стороны налоговых органов. Эта система одновременно играет роль информационной базы для налоговых органов. Проведенные реформы в этом направлении позволяют за счет упрощения и совершенствования налогового администрирования сократить расходы налогоплательщиков на администрирование. Надо отметить, что применением депозитного счета по НДС удалось создать новую и достаточно эффективную систему предотвращения уклонения от уплаты НДС и его незаконного возмещения. Анализ итогов 2008 г. показал, что поступления по этому виду налога в госбюджет по сравнению с 2007 г. увеличились на 76,3\%. При этом за январь-сентябрь 2009 г. поступления по НДС превысили соответствующий период 2007 года на 74,8\%.

Как продолжение предоставляемых услуг, с 1 января 2010 г. начато применение электронных налоговых счетов-фактур. Это осуществляется согласно закону от 19 июня 2009 г. «О внесении дополнений и изменений в Налоговый Кодекс Азербайджанской Республики» и «Правилам применения, учета и использования электронных налоговых счетов-фактур», утвержденных решением Кабинета министров Азербайджанской Республики от 28 сентября 2009 г. ${ }^{1}$.

Согласно статьи 176 «Электронные налоговые счет-фактуры» Налогового Кодекса Азербайджанской Республики лица, которые встали на учет в качестве плательщиков НДС и осуществляют налогооблагаемые операции, обязаны выставлять электронные налоговые счет-фактуры лицам, которые принимают товары, работы или услуги. Лица, не вставшие на учет для целей НДС, не вправе выставлять налоговые счет-фактуры.

Налогоплательщик не позднее 5 дней после поставки товара (выполнения работ, оказания услуг) обязан выставить покупателю товаров (заказчику работ, услуг) электронную налоговую счет-фактуру.

При розничной поставке товаров или оказании услуг покупателям, которые не являются плательщиками НДС, вместо электронной счет-фактуры могут быть выписаны квитанция или чек. Квитанции, чеки, не заказанные, не отпечатанные и не составленные в установленном порядке электронные налоговые счет-фактуры, документы, которыми оформляются операции, проводимые наличными, не могут служить основанием для возмещения

\footnotetext{
${ }^{1}$ Постановление Кабинета Министров Азербайджанской Республики Об утверждении «Правил применения, учета и использования электронных налоговых счет-фактур». Баку, 28 сентября, 2009 г.
} 
DOI: $10.7256 / 1812-8688.2013 .12 .4468$

При цитировании этой статьи сноска на doi обязательна

Налоговые системы зарубежных стран

налога. Документы ввоза, представленные таможенными органами и свидетельствующие об уплате НДС при ввозе, дают основание для возмещения налога.

Ежегодно со стороны налогоплательщиков предоставляется порядка 2 млн. налоговых счет-фактур. По этой причине, для размещения данных в электронных архивах с целью обеспечения бесперебойности работы системы и устройств хранения памяти было приобретено оборудование для создания резервной системы в связи со всевозможными чрезвычайными случаями. В целом, начало деятельности AVİS помимо применения передовых технологий в налоговом администрировании, создало широкие возможности для оказания налогоплательщикам различных электронных услуг. Как уже было отмечено, еще с января 2008 г. был начат обмен электронной информацией с банками. В результате применения этого проекта обеспечивается возможность оперативного открытия банковских счетов налогоплательщиков. Вместе с тем, для налогоплательщиков созданы условия предоставления заявлений посредством интернета с целью открытия банковских счетов и становления на учет по НДС. Помимо этого, система «е-деклараций» уже действует в полном объеме, со стороны плательщиков НДС 99,4\% деклараций предоставляется через интернет.

В будущем планируются реализовать проекты по установке электронных передающих приборов в контрольно-кассовых аппаратах для усиления надзора за наличными расчетами. В результате появится возможность для оперативной передачи в базу данных налоговых органов информации о проводимых наличных расчетах, что, в свою очередь, создаст возможности для повышения эффективности налогового контроля и прозрачности деятельности налогоплательщиков. Кроме этого, согласно Стратегическому Плану, в рамках следующего этапа модернизации налогового контроля внедряется системы «Электронного аудита». В настоящее время для внедрения этой системы изучается международный опыт и внутренние возможности налоговых органов. В тоже время, ведутся подготовительные работы для реализации специального проекта в рамках программы Европейского Союза Twinning и рассчитанного на два года.

25 октября 2007 г. за № 2458 было издано распоряжение Президента Азербайджанской Республики «О мерах по обеспечению организации деятельности субъектов предпринимательской деятельности по принципу «Одного окна»'. В течение двух лет, с введение данного принципа в стране стремительно начало развиваться предпринимательство. С целью упрощения процедур начала бизнеса, данный процесс был начат с участием главы государства 29 декабря 2007 г. Количество регистрационных процедур коммерческих юридических лиц (начало бизнеса) уменьшилось с 13-и до 6-и, затрачиваемой период с 53-х дней до 8-и, включая период, затрачиваемый исключительно на проведение регистрации. Количество документов предоставляемых для проведения регистрации уменьшилось более чем в 5 раз.

С целью дальнейшего улучшения бизнес среды и облегчения процедур, связанных с началом бизнеса, с начала 2008 г. в республике применяется система государственной регистрации хозяйствующих субъектов по принципу «одного окна». Регистрация по принципу «единого окна» привела к росту интереса к предпринимательству, и стала катализатором развития бизнеса. С другой

\footnotetext{
1 Распоряжение Президента Азербайджанской Республики «О мерах по обеспечению организации деятельности субъектов предпринимательской деятельности по принципу «Одного окна». Баку, 25 октября 2007 г.
} 
стороны, применение системы «одного окна» позволило улучшить инвестиционную среду, уменьшить зависимость предпринимателей от госу-дарственных структур, и упростить долгосрочную процедуру регистрации ${ }^{1}$.

Регистрационные данные в централизованном порядке передаются в Государственный Фонд Социальной Защиты, Государственный Статистический Комитет республики и в Государственный Таможенный Комитет, что является большой экономией времени налогоплательщиков. На основании соглашения подписанного с Министерством Экономического Развития, начиная с конца 2008 г. для субъектов предпринимательства была создана возможность получать контрольные книги посредством «Одного окна», не обращаясь в другую государственную структуру. Уже 47.487 налогоплательщика получили контрольные книги с помощью «одного окна».

Азербайджан одной из своих целей определил интеграцию налоговой системы до уровня стандартов, применяемых в Европейском Союзе. В соответствии со стратегией развития национальной экономики, в последние годы достигнуты определенные успехи в совершенствовании налоговой системы, проведены значительные работы с целью доведения налоговой службы до современных европейских стандартов, построения налогового законодательства и администрирования в соответствии с современными требовани- ями. Продолжение этих мероприятий является одним из важнейших аспектов Плана Действий в рамках Политики соседства между Европейским Союзом и Азербайджанской Республикой. В рамках этого Плана действий развитие налоговой системы Азербайджана направлено на гармонизацию с налоговой системой ЕС и общепринятыми стандартами налогового законодательства. Динамичное развитие экономики республики, а также ориентация на европейскую и западную модель отношений создали необходимость для дальнейшего совершенствования налогового законодательства, формирования такого налогового законодательства, которое создает благоприятные возможности для интеграции в Европейский союз для эффективного регулирования налоговой системы. В связи с этим, в «Стратегическом плане совершенствования налогового законодательства и администрирования на 2009-2012 гг.»², а также в других документах предусмотрено проведение мероприятий по доведению налогового законодательства до требований налогового законодательства ЕС. В этом направлении, в частности, в настоящее время осуществляется анализ в сфере совершенствования деятельности налоговых органов и налогового администрирования, повышения эффективности налогового контроля, налоговой службы, а также изучаются возможности их применения в Азербайджане.

\section{Библиография}

\section{1. Налоговый Кодекс Азербайджанской Республики. Баку: 2010 \\ 2. Закон Азербайджанской Республики}

\footnotetext{
1 Распоряжение Президента Азербайджанской Республики «О мерах по обеспечению организации деятельности субъектов предпринимательской деятельности по принципу «Одного окна». Баку, 25 октября 2007
}

«Об электронной подписи и электронном документе». Баку, 4 марта 2004 г. 3. Указ Президента Азербайджанской

\footnotetext{
2 «Стратегический план совершенствования налогового законодательства и администрирования на 2009-2012 гг.», принятый Министерством Налогов Азербайджанской Республики. Баку, 2009 г.
} 
DOI: $10.7256 / 1812-8688.2013 .12 .4468$

При цитировании этой статьи сноска на doi обязательна

Налоговые системы зарубежных стран

Республики об утверждении

Государственной Программы на 20052008 гг. по развитию связи и информационных технологий Азербайджанской Республики (Электронный Азербайджан). Баку, 21 октября 2005 г.

4. Распоряжения Президента Азербайджана от 12 сентября 2005 г. об утверждении «Государственной программы совершенствования налогового администрирования в Азербайджанской Республике на 2005-2007 гг.».

5. Распоряжение Президента Азербайджанской Республики «О мерах по обеспечению организации деятельности субъектов предпринимательской деятельности по принципу «Одного окна». Баку, 25 октября 2007 г.

6. Постановление Кабинета Министров Азербайджанской Республики «Об утверждении Порядка отправления налоговой отчетности в форме электронного документа». Баку, 27 июля 2007 г.

7. Постановление Кабинета Министров Азербайджанской Республики «Об утверждении Правил уплаты НДС при оплате стоимости товаров (работ и услуг), приобретенных по электронному налоговому счету-фактуре, выданному налогоплательщику, ведения учета на депозитном счету НДС, движения НДС, возмещения НДС с операций, совершаемых по этому счету, и его перечисления в государственный бюджет». Баку, 30 декабря 2007 г.

8. Постановление Кабинета Министров Азербайджанской Республики Об утверждении «Правил применения, учета и использования электронных налоговых счет-фактур». Баку, 28 сентября, 2009 г.

9. «Стратегический план совершенствования налогового законодательства и администрирования на 2009-2012 гг.», принятый Министерством Налогов Азербайджанской Республики. Баку, 2009 г.

10. Маммадов Э.Ф. Теоретические основы и принципы налогового администрирования (на азерб. языке). //Журнал «Аудит», Вып. 3-4, 2007, c.11-15.

11. www. taxes. gov.az

\section{References (transliterated)}

1. Nalogovyi Kodeks Azerbaidzhanskoi Respubliki. Baku: 2010

2. Zakon Azerbaidzhanskoi Respubliki «Ob elektronnoi podpisi i elektronnom dokumente». Baku, 4 marta 2004 g.

3. Ukaz Prezidenta Azerbaidzhanskoi Respubliki ob utverzhdenii Gosudarstvennoi Programmy na 2005-2008 gg. po razvitiyu svyazi i informatsionnykh tekhnologii Azerbaidzhanskoi Respubliki (Elektronnyi Azerbaidzhan). Baku, 21 oktyabrya 2005 g.

4. Rasporyazheniya Prezidenta

Azerbaidzhana ot 12 sentyabrya 2005 g. ob utverzhdenii «Gosudarstvennoi programmy sovershenstvovaniya nalogovogo administrirovaniya v Azerbaidzhanskoi Respublike na 2005-2007 gg.»».

5. Rasporyazhenie Prezidenta Azerbaidzhanskoi Respubliki «O merakh po obespecheniyu organizatsii deyatel'nosti sub"ektov predprinimatel'skoi deyatel'nosti po printsipu «Odnogo okna». Baku, 25 oktyabrya $2007 \mathrm{~g}$.

6. Postanovlenie Kabineta Ministrov Azerbaidzhanskoi Respubliki «Ob utverzhdenii Poryadka otpravleniya nalogovoi otchetnosti $v$ forme elektronnogo 
dokumenta». Baku, 27 iyulya $2007 \mathrm{~g}$.

7. Postanovlenie Kabineta Ministrov Azerbaidzhanskoi Respubliki «Ob utverzhdenii Pravil uplaty NDS pri oplate stoimosti tovarov (rabot i uslug), priobretennykh po elektronnomu nalogovomu schetu-fakture, vydannomu nalogoplatel'shchiku, vedeniya ucheta na depozitnom schetu NDS, dvizheniya NDS, vozmeshcheniya NDS s operatsii, sovershaemykh po etomu schetu, i ego perechisleniya $\mathrm{v}$ gosudarstvennyi byudzhet». Baku, 30 dekabrya $2007 \mathrm{~g}$.

8. Postanovlenie Kabineta Ministrov
Azerbaidzhanskoi Respubliki Ob utverzhdenii «Pravil primeneniya, ucheta $i$ ispol'zovaniya elektronnykh nalogovykh schet-faktur». Baku, 28 sentyabrya, $2009 \mathrm{~g}$.

9. «Strategicheskii plan sovershenstvovaniya nalogovogo zakonodatel'stva i administrirovaniya na 2009-2012 gg.»), prinyatyi Ministerstvom Nalogov Azerbaidzhanskoi Respubliki. Baku, 2009 g.

10. Mammadov E. F. Teoreticheskie osnovy i printsipy nalogovogo administrirovaniya (na azerb. yazyke). //Zhurnal «Audit», Vyp. 3-4, 2007, s.11-15.

11. www. taxes. gov.az 